\title{
THE ROLE OF BURIED OH SITES IN THE RESPONSE MECHANISM OF INORGANIC-GATE pH-SENSITIVE ISFETs
}

\author{
LUC BOUSSE* and PIET BERGVELD \\ Department of Electrical Engineering, Twente University of Technology, $P B 217$, \\ $7500 A E$ Enschede (The Netherlands)
}

(Recelved September 21, 1983, in revised form September 19, 1984, accepted September 26,1984 )

\section{Abstract}

The models proposed in the literature on the mechanism of operation of inorganic-gate pH-sensitive ISFETs can be divided in three categories those involving changes at the $\mathrm{S} 1$ /nsulator interface, those involving bulk ionic diffusion and those based on reactions of surface sites The furst two categories imply a time response limited by diffusion through the gate insulator Time response data on $\mathrm{Al}_{2} \mathrm{O}_{3}$-gate ISFETs show that the intrinsic response time is of the order of a few millseconds or faster Published data for other insulators are similar The diffusion coefficient for $\mathrm{H}^{+}$diffusion in $\mathrm{SiO}_{2}$ is much too low to explain this fast response, and for $\mathrm{Al}_{2} \mathrm{O}_{3}$ and $\mathrm{Sr}_{3} \mathrm{~N}_{4}$ no $\mathrm{H}^{+}$movement can be detected at low temperatures $\mathrm{Gel}$ layer formation cannot increase ionic moblity sufficiently to explain the observed response tumes Therefore we conclude that surface effects must be responsible for the fast $\mathrm{pH}$ response We propose that an additional slow response resulting in hysteresis as observed in $\mathrm{SiO}_{2}$-gate ISFETs, as well as a decreased sensitivity for higher $\mathrm{pH}$ values, are due to the presence of $\mathrm{OH}$ sites buried beneath the surface These interior $\mathrm{OH}$ sites can be created by steam oxidation or by exposure to the aqueous electrolyte

\section{Introduction}

Since the furst report of a chemically sensitive electronic device by Bergveld in 1970 [1], research has progressed along two lines extension of the sensitivity to ions other than $\mathrm{H}^{+}$ions (for this aspect, see Janata's reviews $[2,3])$, and explanation of the mechanism of operation of the simple pHsensitive morganic-gate ISFET [4-12] This paper concerns the second aspect, for which various models have been proposed Some of these only claim to explain certain aspects of the response, such as drift, whlle others

*Present address Stanford Electronies Laboratories, AEL113C, Stanford University, CA 94305 , U S A 
have attempted to explain quantitatively potentıal/pH measurements These models can be classified according to the location where the mechanism of $\mathrm{pH}$-sensitivity is presumed to occur

(1) Models based on the reactivity of the insulator surface Here it is considered that surface sites on the insulator react with ions in the solution This creates charge and potential in the electrical double layer in the electrolyte at the interface with the insulator Kelly [4] first suggested that this is the main mechanism of operation of ISFET pH sensors, but gave no quantitative theory Siu and Cobbold [8] applied the site-binding theory as proposed by Yates et al [13] in the field of colloid chemistry We have described such a site-dissociation theory in detal, and verified its valıdity [11, 12]

(2) Models based on the presence of mobile lons in the insulating layer Some papers implicitly proposed such a model by considering a quantity such as $\mu^{\alpha x}{ }_{\mathrm{H}^{+}}$, the chemical potential of $\mathrm{H}^{+}$ions in the insulator [6] This implies the existence of a transport mechanism, at least up to a certain distance inside the insulator, to establish the required thermodynamic equilibrium, and leads directly to a Nernst equation Some authors have used the Nernst equation without further comment [14], or by referring to the simlarity with the glass electrode [15]

(3) Models based on the modification of the $\mathrm{S}_{1} / \mathrm{SiO}_{2}$ interface through a $\mathrm{pH}$-controlled change in the surface state density va transport of a hydrogen-bearing species This has been explicitly considered by Revesz [5], de Rool] and Bergveld [7, 10] and Barabash and Cobbold [16]

It is clear that the main point of difference lies in whether a bulk or surface mechanism is assumed Type (3) theories can be considered a more extreme form of type (2), since transport of hydrogen-bearing species through the entire insulator is assumed to change the surface state density However, in type (3) theories as opposed to type (2), the transported species might be neutral The model proposed by Lauks [9], involving a very thin ionically conducting gel-hke layer, can be considered to be intermediate between types 1 and 2 The various opmions that exist on the mechanism of ISFET operation can be seen as an aspect of a more general discussion existing in collold science on the nature of the oxide/electrolyte interface Lyklema [17] and Perram [18] argue in favour of a gel layer model (type (2)) in which an outer porous layer of the oxide contains both the oxide charge and the interfacial potential The alternative, consisting of purely surface reactions (type (1)), is the site-binding model [13], which found experimental support in the work of Yates and Healy [19] and Smit et al [20] Yates' work llustrated the importance of sample preparation, since he found that both porous and non-porous $\mathrm{S}_{1} \mathrm{O}_{2}$ collonds can be prepared

For some models, predicted potential $/ \mathrm{pH}$ characterıstıcs have been explicitly presented $[9,11,12]$, and agree to some extent with experiment Problems remain, however The site-dissociation model cannot explain the sub-Nernstian $\mathrm{pH}$ response of $\mathrm{SiO}_{2}$ far from its point of zero charge, which has been widely observed No satisfactory model has been put forward to 
explain the drift and hysteresis which are always present to some extent, especially with $\mathrm{SiO}_{2}$ Since potential/pH data are insufficient to identify the response mechanism involved, more data are needed We suggest that information on the speed of response to $\mathrm{pH}$ steps can help identify the mechanisms involved Therefore, we will review the avalable measurements of ISFET response speed by ourselves and others Our aim will be to present a general picture of the role of various mechanisms which we believe can explain most of the reported data on $\mathrm{SiO}_{2}$ and other insulators

\section{Response time of inorganic-gate ISFETs}

The response of an ISFET to a fast $\mathrm{pH}$ step is in general characterized by a fast response, followed by a slow change in the same direction, and ultimately a drift which is hnear or logarithmic with time The precise definition of what is meant by the fast or slow response of an ISFET can be a subject of some confusion, we have defined the fast response time to be the time needed for the output to change from $10 \%$ to $90 \%$ of the total variation The slow response is the extra time needed for the response to reach $100 \%$ Other authors have used other definitions, which can explain some variations in reported results It is clear, however, that there is a large difference between the slow and fast time constants, as has also been found with oxide colloids [21] This large difference is an important factor in the considerations which follow

\section{Fast response}

There have been relatively few published attempts to find an intrinsic ISFET response speed We have recently published data for our $\mathrm{Al}_{2} \mathrm{O}_{3}$ ISFETs which showed that the intrinsic response speed must be at least in the millisecond range, and could be considerably faster $[22,23]$ The measured response time was determined by the steepness of the $\mathrm{pH}$ step in the electrolyte, and not by the detector itself McBride et al [24] have shown part of a transient measured by directing a jet of electrolyte on an $\mathrm{Si}_{3} \mathrm{~N}_{4}$-gate ISFET The response time was of the order of $1 \mathrm{~ms}$ The time response of $\mathrm{SiO}_{2}$-gate devices has not been studied as carefully, Moss et al [25] report values around $200 \mathrm{~ms}$ and above Bergveld has found a response time of $40 \mathrm{~ms}$ for an $\mathrm{SiO}_{2}$ device, obtaned by an open flow method [26] Leistiko [27] mentions a response time of milliseconds for his $\mathrm{SiO}_{2}$-gate devices As before, in all these cases, the response was probably determined by the speed of the $\mathrm{pH}$ variation itself, and not by the ISFET These results therefore provide an upper limit to the intrinsic response time In our opınıon, inorganic-gate pH-ISFETs have intrinsic response times of the order of one millisecond or faster

\section{Slow response}

The studies mentioned above were only concerned with the fast part of the response after a pH step There is also a slow response, particularly for 
$\mathrm{SiO}_{2}$ Apart from a continuous drift of the threshold voltage, which does not depend on $\mathrm{pH}$, there is a hysteresis in the $\mathrm{pH}$ response in the direction which corresponds to a memory effect Only a few authors have reported this effect quantitatively, Leistiko [27] reports a very large hysteresis for an $\mathrm{SiO}_{2}$ gate device, of the order of $25 \%$ of the total potential response for a measurement between $\mathrm{pH} 1$ and 10 Schenck's measurements on $\mathrm{S}_{1} \mathrm{O}_{2}$-gate devices show a hysteresis of about $12 \%$ of the total response [28], in a much smaller $\mathrm{pH}$ range In this respect the supenonty of $\mathrm{S}_{3} \mathrm{~N}_{4}$ and especially $\mathrm{Al}_{2} \mathrm{O}_{3}$ gates is very clear Abe et al [29] report a hysteresis of $03 \%$ for $\mathrm{Al}_{2} \mathrm{O}_{3}$-gate ISFETs These values are only indicative of the order of magnitude involved, and probably depend on factors such as the speed and the extent of the $\mathrm{pH}$ scan Our own measurements of hysteresis loops for $\mathrm{Al}_{2} \mathrm{O}_{3}$ gate ISFETs [11] took several hours, and Abe et al [29] use pH exposures lasting 60 minutes, none of the other authors mentioned above gives any indication of the time involved in his measurements

The presence of a memory effect shows that a small part of the pH response is very slow, and occurs with a delay of the order of minutes to hours after the $\mathrm{pH}$ variation Only for $\mathrm{SiO}_{2}$ is this memory effect considerable, for the other insulators that have been evaluated as $\mathrm{pH}$-sensitive gate layers it is much smaller

\section{Estimation of response time due to diffusion mechanisms}

In this section we will derive an estimate of the time response expected for a type (2) response mechanism, le, considering only bulk migration effects The purpose is to verify whether such a mechanism can explain the observed fast response times Therefore we will assume that the diffusion length is very small, 3 to $10 \mathrm{~nm}$ as assumed in [9], which is expected to give the fastest response Since we require only an order of magnitude, the model will be kept as simple as possible Diffusion of protons from an electrolyte solution into an oxıde surface has been considered earlier by Bérubé $e t a l$ [21], and we will adopt the principal features of their treatment We wlll focus the discussion on the diffusion of $\mathrm{H}^{+}$lons, because these are often thought to be relatively mobile In models where it is assumed that charge neutrality is maintained [9], diffusion of $\mathrm{OH}^{-}$should also be considered These ions are in general much less mobile than cations, certainly in $\mathrm{SlO}_{2}$

The change in $\mathrm{H}^{+}$concentration in response time experiments such as those described above is typically several orders of magnitude Diffusion in the ISFET insulator can then be viewed as the switching on at $t=0$ of an infinite source at the insulator/electrolyte interface This leads to an error function profile of the diffusing substance

$c(x, t)=c_{0} \operatorname{erfc}\left(\frac{x}{2 \sqrt{D t}}\right)$

We adopt the usual definition of the diffusion length $L_{\mathrm{D}}$ as 
$L_{\mathrm{D}}=2 \sqrt{\overline{D t}}$

which corresponds to the distance where $c$ is equal to $016 c_{0}$, although the steepness of the diffusion profile makes $L_{\mathrm{D}}$ insensitive to the exact criterion used in its definition The electrical field in the insulator will cause drift of charged particles, and this will enhance or counteract the diffusion, depending on the sign of the 1ons and field involved Usual working conditions in ISFETs correspond to a field of about $10^{5} \mathrm{~V} / \mathrm{cm}$, and it can be verified that when $L_{\mathrm{D}}$ is in the 3 to $10 \mathrm{~nm}$ range, the influence of drift is smaller than diffusion Therefore we will estimate the response time only in terms of a diffusion process

The previous discussion ignores the possibility of reactions between the diffusing species and the insulator, in practice this will only be true for diffusion of noble gases Cations in $\mathrm{SlO}_{2}$ are known to be trapped, for instance at non-bridging oxygens, or at aluminosilicate groups if $\mathrm{Al}$ contamination is present We will assume that a simple reaction exists between trap sites and diffusing species, which achieves equilibrium much faster than the diffusion

free trap site + ion $\leftrightarrows$ trapped ion

With $c$ the concentration of trapped ions, $f$ the concentration of free ions, $s$ the density of empty trap sites, $K$ the reaction equilibrium constant, we find

$c=K s f$

The influence of a first-order reaction on diffusion is known from standard theory [30], in the simple case of $c \gg f$, it is found that the profile of the diffusing species is again described by eqn (1), provided an effective diffusion coefficient is used instead of $D$

$D_{\text {eff }}=\frac{D}{K s}$

which is by assumption much smaller than $D$ The penetration depth is thus given by

$L_{\mathrm{D}}=2 \sqrt{D_{\text {eff }} t}$

Experimentally, $D_{\text {eff }}$ is determined by bulk diffusion experiments which include the trapping of ions This is a different quantity from $D$, which is the diffusivity without the influence of trapping $D$ can be measured by transit time experiments in thin $\mathrm{SiO}_{2}$ films where trapping occurs mainly at the interfaces (see next section) It is important to remember, however, that in general ionic migration is influenced by trapping, and that therefore $D_{\text {eff }}$ should be used to describe it

Assuming $L_{\mathrm{D}}$ is $3 \mathrm{~nm}$, it follows from eqn (6) that $D_{\text {eff }}>10^{-12} \mathrm{~cm}^{2} / \mathrm{s}$ is required for response times below $10 \mathrm{~ms}$ The following sections will examine whether this is possible in the insulators for which kinetic data are avalable Conversely, information about the diffusion coefficient can be 
translated into the time constant expected for a bulk diffusion pH-response mechanism

Experiments on $\mathrm{Na}^{+}$mobility in thin $\mathrm{SiO}_{2}$ fllms show that an equilibrium such as the one assumed in eqn (3) does not necessarly occur, but that the kinetics of the release of ions from traps dominate ionic motion [31] This is clearly illustrated by DiMaria [32], who showed that at room temperature sodium was exclusively trapped at the interfaces of a thin $\mathrm{SiO}_{2}$ film, and not in the bulk This conclusion probably applies to an even greater extent to $\mathrm{H}^{+}$motion Therefore, eqn (6) will tend to underestimate the response time at low temperatures or fields

\section{Ionic diffusion coefficients in $\mathrm{SiO}_{2}$}

Although our main concern is the movement of $\mathrm{H}^{+}$lons, the diffusion of $\mathrm{Na}^{+}$is much better known, and serves as a convenient starting point for comparisons It is well known that alkalı 1ons, in particular sodium, are by far the fastest moving species in vitreous silica and quartz Values of $D_{\text {eff }}$ for sodium determined in bulk samples are summarized in Table 1 Extrapolation to room temperature gives a value of $10^{-20}$ to $10^{-22} \mathrm{~cm}^{2} / 5$ All vitreous silica samples in these experiments contained sufficient Al contamination to ensure complete cation trapping at aluminosilicate sites Recent measurements of the druft mobulity in thin $\mathrm{S}_{1} \mathrm{O}_{2}$ films give values of the room temperature $D$ that are much higher (see Table 1), since no trapping is involved It is interesting to note that early measurements in thin films by Snow et al [33], in which no separation was made between detrapping and drift, agreed with values in bulk silica This suggests that the traps at $\mathrm{Al} / \mathrm{SiO}_{2}$ interfaces have similar properties to those in bulk silica, possibly due to the presence of aluminosilicate groups in both cases

Motion of $\mathrm{H}^{+}$lons in thin $\mathrm{SiO}_{2}$ films is still a controversial subject Several authors have reported charge movements which they ascribe to $\mathrm{H}^{+}$ motion [34-36] The basic problem involved, however, is that electrically active amounts of contamination are too small to be directly identifiable by analytical chemical techniques It has been shown by Raider and Flitsch [37] that ethanol (a method intended to introduce $\mathrm{H}^{+}$1ons) contains enough sodium to prove that charge motion is due to that ion, and not $\mathrm{H}^{+}$Ethanol which had been purified to exclude $\mathrm{Na}^{+}$did not introduce mobile ions in $\mathrm{SiO}_{2}$ [37] Therefore, Hofstein's fast-moving species has been identified as sodium in Table 1 It is clear that Hofstein's $\mathrm{Na}^{+}$diffusion coefficient is in reasonable agreement with later determinations Boudry and Stagg [31], who verified that $\mathrm{Na}^{+}, \mathrm{K}^{+}$and $\mathrm{Ll}^{+}$were all more or less moblle in $\mathrm{SiO}_{2}$, did not find any proton mobility The same result was obtained by Hillen [38], who shallowly implanted $\mathrm{H}^{+}$lons in an $\mathrm{SiO}_{2}$ layer In fact, these results are confirmations of earlier work by Yurash and Deal [39], who exposed $\mathrm{SiO}_{2}$ layers to strong acids without introducing instability The absence of $\mathrm{H}^{+}$ movement can be due to very low drift mobility, or to very strong trapping 
TABLE 1

Diffusion coefficients of $\mathrm{Na}^{+}$in $\mathrm{SiO}_{2}$ The drift mobility is measured in thin thermally grown films, and provides values of $D$ The lower part of the Table shows measurements in bulk vitreous silica, which include the effect of trapping, and are therefore measurements of $D_{\text {eff }}$

\begin{tabular}{|c|c|c|c|c|}
\hline Method and investigators & $\begin{array}{l}D_{0} \\
\left(\mathrm{~cm}^{2} / \mathrm{s}\right)\end{array}$ & $\begin{array}{l}E_{\mathrm{A}} \\
(\mathrm{eV})\end{array}$ & $\begin{array}{l}D\left(25^{\circ} \mathrm{C}\right) \\
\left(\mathrm{cm}^{2} / \mathrm{s}\right)\end{array}$ & $\begin{array}{l}\text { Temperature range } \\
\left({ }^{\circ} \mathrm{C}\right)\end{array}$ \\
\hline \multicolumn{5}{|l|}{ Drift mobility of $\mathrm{Na}^{+}$} \\
\hline Stagg $[68]$ & $33 \times 10^{-2}$ & 066 & $23 \times 10^{-13}$ & $37 \quad 177$ \\
\hline Kriegler and Devenyı [69] & $14 \times 10^{-2}$ & 063 & $32 \times 10^{-13}$ & $28-160$ \\
\hline Hofstein $[70]$ & 10 & 070 & $15 \times 10^{-12}$ & $40-100$ \\
\hline \multicolumn{5}{|l|}{$\begin{array}{l}\mathrm{Na}^{+} \text {tracer diffusion in } \\
\quad \text { vitreous sillca }\end{array}$} \\
\hline \multicolumn{5}{|l|}{ Frischat $[71]$} \\
\hline \multirow[t]{2}{*}{ Type I silica } & 21 & 122 & $51 \times 10^{-21}$ & $170-250$ \\
\hline & 037 & 112 & $47 \times 10^{-20}$ & $250-600$ \\
\hline Type II silica & 13 & 117 & $22 \times 10^{-20}$ & 250600 \\
\hline $\begin{array}{l}\text { Electrolysts of vitreous silica } \\
\text { Doremus [ } 40 \text { ] }\end{array}$ & $56 \times 10^{3}$ & 152 & $12 \times 10^{-22}$ & $130-280$ \\
\hline
\end{tabular}

The small size of $\mathrm{H}^{+}$lons obviously makes the latter much more likely, as discussed by Doremus [40,41]

In the study of bulk sllica or glasses it is generally accepted that $\mathrm{H}^{+}$is less moblle than alkalı lons Jorgensen and Norton [42] have detected $\mathrm{H}^{+}$ motion in vitreous silica at $1000{ }^{\circ} \mathrm{C}$, finding a $D_{\text {eff }}$ which 1 about 700 times lower than that for $\mathrm{Na}^{+}$at that temperature At about the same temperature, Hetherington et al [43] reported electrical conductivity a factor of $10^{4}$ lower in vitreous sllica where $\mathrm{Na}^{+}$ions had been replaced by $\mathrm{H}^{+}$Many other results on lonic mobility have been obtained in the study of electrode glasses It must be remembered, though, that in these glasses diffusion is several orders of magnitude faster than in pure $\mathrm{SiO}_{2}$ The main interest in these measurements is the ratio between $\mathrm{H}^{+}$mobility and that of the alkall Ions $\mathrm{H}^{+}$is systematically found to be less mobile (see Table 2), and compared to $\mathrm{Na}^{+}$the mobility ratio is about $10^{3}$ to $10^{4}$ Applying this ratio to the value of $D_{\text {eff }}\left(\mathrm{Na}^{+}\right)$of pure $\mathrm{SiO}_{2}$ gives an estimated $D_{\text {eff }}\left(\mathrm{H}^{+}\right)$of $10^{-24}$ to $10^{-23} \mathrm{~cm}^{2} / \mathrm{s}$ at $25{ }^{\circ} \mathrm{C}$ (Note that this corresponds to a diffusion length of $02 \mathrm{~nm}$ in one year )

The experimental results of Baucke [44] are particularly relevant in this context, because they have been obtained with glass surfaces exposed to electrolyte solutions These are the operating conditions for ISFETs, as opposed to most studies of ionic mobility which are carried out on samples not exposed to water Baucke found that even in surface layers where all lithium ions had been replaced by $\mathrm{H}^{+}$lons, $\mathrm{Li}^{+}$mobility was still greater than $\mathrm{H}^{+}$mobility The $\mathrm{H}^{+}$diffusion coefficient in such a layer was about 
TABLE 2

Ratıo of diffusion coefficients of alkali ions and $\mathrm{H}^{+}$in $\mathrm{SiO}_{2}$ and silicate glasses

\begin{tabular}{llll}
\hline Material and investigators & Alkalı ion, $\mathrm{A}^{+}$ & $\begin{array}{l}\text { Ratio } \\
D_{\mathrm{eff}}\left(\mathrm{A}^{+}\right) / D_{\mathrm{eff}}\left(\mathrm{H}^{+}\right)\end{array}$ & $\begin{array}{l}\text { Temperature of } \\
\text { measurement, }{ }^{\circ} \mathrm{C}\end{array}$ \\
\hline $\begin{array}{l}\text { Vitreous sulica } \\
\text { Hetherington et al [43] }\end{array}$ & $\mathrm{Na}^{+}$ & $10^{4}$ & 1050 \\
Jorgensen and Norton [42] & $\mathrm{Na}^{+}$ & 700 & 1000 \\
Electrode glasses & & & 50 \\
Doremus [47] & $\mathrm{Li}^{+}$ & 2600 & 50 \\
& $\mathrm{Na}^{+}$ & $10^{4}$ to $10^{5}$ & 50 \\
$\mathrm{~K}^{+}$ & 1 to 10 & 50 \\
\hline
\end{tabular}

$10^{-17} \mathrm{~cm}^{2} / \mathrm{s}$ at $50^{\circ} \mathrm{C}$, which is higher than extrapolated above for pure $\mathrm{SiO}_{2}$ due to the very high concentration of non-bridging oxygens in an electrode glass surface This indicates that the $\mathrm{H}^{+}$diffusion coefficient in the surface of a layer of pure $\mathrm{SiO}_{2}$ depends on the number of $\mathrm{OH}$ groups present, but will always be much smaller than the minimal value of $10^{-12} \mathrm{~cm}^{2} / \mathrm{s}$ derived above to explain millisecond $\mathrm{pH}$ response times

Information on diffusion in $\mathrm{Sl}_{3} \mathrm{~N}_{4}$ and $\mathrm{Al}_{2} \mathrm{O}_{3}$, two other gate materials used in ISFETs, is much more limited than for $\mathrm{S}_{1} \mathrm{O}_{2}$ This is no doubt due to the much smaller diffusion coefficients involved, which means that as a rule no movement of any species can be observed It is known that both $\mathrm{Al}_{2} \mathrm{O}_{3}$ and $\mathrm{Sl}_{3} \mathrm{~N}_{4}$ films are barriers against ionic diffusion $A$ good illustration is the work of $\mathrm{B} \phi$ ttiger et $a l$ [45] who at $500{ }^{\circ} \mathrm{C}$ found no movement of $\mathrm{H}^{+}$ions implanted in $\mathrm{Al}_{2} \mathrm{O}_{3}$

\section{Formation of a gel layer or of buried $\mathrm{OH}$ sites}

\section{Gel layers in glasses}

It has often been proposed that on the surface of electrode glasses a hydrated gel-hke layer forms after sufficient exposure to water This layer has a sufficiently open structure that ionic mobilities are much higher than in the bulk material These glasses contain alkalı oxides (typically lithia), and other network formers or network modifiers, with a balance of around $70 \% \mathrm{~S}_{1} \mathrm{O}_{2}$ The surface of such a glass in contact with an aqueous electrolyte is attacked by lon exchange Using $L_{1}$ as an example

$\equiv \mathrm{S1}-\mathrm{OL}_{1}+\mathrm{H}_{2} \mathrm{O} \longrightarrow \equiv \mathrm{S}_{1}-\mathrm{OH}+\mathrm{L} 1 \mathrm{OH}$

Due to the different sizes of $H$ and $L_{1}$, this creates a distorted, open, network, which in turn causes continuing hydration Wikby [46] found that electrical conductivity in a hydrated surface gel layer on an electrode glass was a factor of the order of five higher than in bulk glass Since conductivity 
is determined by alkali ion mobulities, this result suggests that diffusion coefficients can be no more than one order of magnitude higher inside a gel layer, which would leave the conclusions of the previous sections unaffected The open structure of a gel layer causes it to dissolve relatively easily in water, with speeds of typically around $10^{-14} \mathrm{~m} / \mathrm{s}$ In steady state, the rate of formation of the gel layer is similar to the dissolution rate [47] Therefore, data of glass dissolution rates can be used to estimate speed of gel layer formation

\section{Burled $\mathrm{OH}$ sites in $\mathrm{SlO}_{2}$}

The case of $\mathrm{SiO}_{2}$, with which we are concerned, is quite different due to the absence of impurities and the corresponding ion exchange mechanism (7) This is clearly illustrated by the low dissolution rate of $\mathrm{SiO}_{2}$ in water Van Lier et al [48] found a dissolution rate of quartz in distilled water of $45 \times 10^{-21} \mathrm{~m} / \mathrm{s}$ at room temperature Takıng account of the fact that amorphous $\mathrm{SiO}_{2}$ dissolves about 13 times faster [48, 49], and of the increase of dissolution rate with ionic strength (a factor of 67 according to [49]), the rate of dissolution of amorphous $\mathrm{SiO}_{2}$ in $01 \mathrm{M} \mathrm{NaCl}$ is $4 \times 10^{-18} \mathrm{~m} / \mathrm{s}$ This amounts to about $01 \mathrm{~nm}$ per year, and can hardly be detected experimentally This means that water cannot dissolve the $\mathrm{SiO}_{2}$ network, and that no distorted surface gel layer can form on the surface Steun [50] also argues that $\mathrm{SiO}_{2}$ cannot be assumed to behave in the same way as glasses There is also more direct experimental evidence avalable on this point The formation of a strongly conductive, 3 to $10 \mathrm{~nm}$ thick layer at the oxide/electrolyte interface would influence the capacitance of electrolyte/thin $\mathrm{SiO}_{2}$ /silicon structures, which has not been observed $[51,52]$

The previous argument does not mean that no interaction at all between $\mathrm{SiO}_{2}$ and water is expected It is known, in fact, that water diffuses into thin thermally-grown $\mathrm{SiO}_{2}$ layers with a low activation energy, even at room temperature [53-55] Most of this water reacts with the $\mathrm{S}_{1} \mathrm{O}_{2}$ structure to form $\mathrm{S}-\mathrm{OH}$ sites [54], leading to a high concentration of non-bridging oxygen sites near the $\mathrm{SiO}_{2}$ surface, especially for surfaces exposed to an aqueous electrolyte According to Hartstem's [54] or Pfeffer et al 's [55] results, the concentration of $\mathrm{S}_{1}-\mathrm{OH}$ near the surface is in the $10^{19}$ to $10^{20}$ $\mathrm{cm}^{-3}$ range Let us assume, for the purpose of llustration, that $\mathrm{OH}$ groups in the outermost four layers of $\mathrm{SiO}_{4}$ tetrahedra can react with $\mathrm{H}^{+}$ions from the solution, possibly with long time constants The thickness of these layers is about $09 \mathrm{~nm}$, and they will therefore contain of the order of $10^{13} \mathrm{~cm}^{-2}$ of $\mathrm{S} 1-\mathrm{OH}$ groups, assuming a surface density of $10^{20} \mathrm{~cm}^{-3}$ This figure could be even higher for the furst few $\mathrm{nm}$ of oxides immersed in water, especially if we bear in mind Pfeffer's report of a thin outer layer with very high hydrogen content Although this number of $\mathrm{S}_{1}-\mathrm{OH}$ sites buried below the surface remains small compared to the number of sites on the surface $\left(5 \times 10^{14} \mathrm{~cm}^{-2}\right.$ [13]), a slow response of these buried sites to electrolyte $\mathrm{pH}$ variations could explain the hysteresis effects found in $\mathrm{S}_{2} \mathrm{O}_{2}$-gate ISFETs

Note that we distinguish between a thin layer of buried sites, existing near the $\mathrm{S}_{1} \mathrm{O}_{2}$ surface, and a gel layer in the surface of glasses where alkali 
Ions are involved in an ion cxchange mechanism with the electrolyte Summarizing, we conclude that the presence of an aqueous electrolyte might create a sufficient number of $\mathrm{OH}$ groups beneath the $\mathrm{SrO}_{2}$ surface to cause the observed hysteresis

\section{Other insulators}

For substances other than $\mathrm{SiO}_{2}$ or glasses little is known about the possible formation of gel layers on their surface In particular, it seems that the $\mathrm{Sl}_{3} \mathrm{~N}_{4}$ /electrolyte interface has only been studied in the context of 1onsensitive devices For both $\mathrm{S}_{3} \mathrm{~N}_{4}$ and $\mathrm{Al}_{2} \mathrm{O}_{3}$, however, it is known that their resistance to hydration when exposed to water is good, particularly for $\mathrm{Al}_{2} \mathrm{O}_{3}$ [56] It has been shown by Gruen et al [57] that no $\mathrm{OH}$ groups are formed by exposing untreated sapphire to bolling water Therefore no high concentration of internal $\mathrm{OH}$ groups is expected in the insulator of $\gamma-\mathrm{Al}_{2} \mathrm{O}_{3}$ ISFETs

\section{Drift mechanisms}

The phenomenon usually called drift is a slow, contmuous, change of the threshold voltage of an ISFET in the same direction It is difficult to identify the cause of this phenomenon, which could be either a surface or a bulk effect, or both Some possible causes of drift are, amongst other possibilities

(1) Variation of the surface state density $\left(D_{1 \mathrm{t}}\right)$ at the $\mathrm{Sl} / \mathrm{SlO}_{2}$ interface, as mentioned above Some authors, however, do not see any $D_{1 \mathrm{t}}$ changes [60, 61] Barabash [16] only found a $\mathrm{pH}$ influence for $\mathrm{pH}=6$

(2) Slow surface effects, such as the rehydration of an $\mathrm{SiO}_{2}$ surface that is partially dehydrated [49] Bérubé et al [21] have also suggested that slow changes occur on oxide surfaces, such as ion exchange involving $\mathrm{OH}^{-}$ions

(3) Drift of sodium lons under the influence of the insulator field Given that $D_{\text {eff }}\left(\mathrm{Na}^{+}\right)$is around $10^{-20} \mathrm{~cm}^{2} / \mathrm{s}$ (Table 1), it is clear that a bulk redistribution of sodium would be too slow to be noticeable It is known, however, that a sodium ion which has left a trap near the edge of the $\mathrm{S}_{1} \mathrm{O}_{2}$ can drift rapidly to the other interface [31]

(4) Injection of electrons from the electroly te at strong anodic polarizations, creating negative space charge inside $\mathrm{S}_{1} \mathrm{O}_{2}$ films This has been more extensively discussed elsewhere [52,62]

These mechanisms have in common the property that they have at most a weak dependence on electrolyte $\mathrm{pH}$, and cannot explain the hysteresis found in ISFETs, which is a memory effect or a slow response to $\mathrm{pH}$ changes 


\section{Discussion and conclusion}

The results presented here make it clear that bulk diffusion mechanisms cannot explain the fast time response of ISFET $\mathrm{pH}$ sensors with inorganic gates All diffusion coefficients $D_{\text {eff }}$ are very low, even for $\mathrm{SlO}_{2}$ which has a relatively open structure This conclusion is similar to those reached in the study of other msulator/electrolyte systems It has been reported by Baucke [58] that the glass electrode potential also originates mainly from the dissociation of surface $\mathrm{S}-\mathrm{OH}$ groups This would explain why glass electrodes also have a comparatively fast time response The role of surface $\mathrm{OH}$ groups in the $\mathrm{pH}$ response of oxide collonds is also generally accepted [59]

As listed in Section 6, there are many possible explanations of drift effects It is more difficult to explain hysteresis, which is a delayed reaction to $\mathrm{pH}$ changes However, the presence of buried $\mathrm{OH}$ sites, which certainly exist in $\mathrm{SiO}_{2}$, provides a simple qualitative explanation The hypothesis that the slow response is due to bulk $\mathrm{OH}$ groups also explains the marked difference in behaviour between $\mathrm{SiO}_{2}$ and the other materials that have been tried in ISFETs Of these materials, $\mathrm{SiO}_{2}$ is the only oxide that will absorb considerable amounts of water at room temperature, with creation of internal $\mathrm{OH}$ groups Correspondingly, $\mathrm{SiO}_{2}$-gate ISFETs have by far the worst hysteresis

We suggest therefore that hysteresis is correlated with the presence of internal $\mathrm{OH}$ groups near the surface, although this does not constitute a gel layer There is evidence that internal $\mathrm{OH}$ groups are also correlated with another unexplained aspect of $\mathrm{SiO}_{2}$-ISFETs, namely the differing experimental results reported for their $\mathrm{pH}$ sensitivity far from the $\mathrm{pH}$ of zero charge ( $l$ e, above $\mathrm{pH}=5$ ) The site-dissociation model predicts a nearNernstian $\mathrm{pH}$ response for $\mathrm{SiO}_{2}$ in this $\mathrm{pH}$ range Although some publications $[8,63]$ report slopes close to Nernstian in this region, many authors never see slopes higher than 30 to $40 \mathrm{mV} / \mathrm{pH}[11,27,28,60,64,65]$ for $\mathrm{SiO}_{2}$ surfaces Clearly, the site-dissociation model is not always obeyed, and some other factor can influence the results at high $\mathrm{pH}$ values Insight into the nature of this factor is provided by recent results by Vlasov et al [66] He has made $\mathrm{SiO}_{2}$-gate ISFETs with varying numbers of $\mathrm{OH}$ groups incorporated in the oxide layer [66] For $\mathrm{pH}<4$ the sensitivity was $\mathrm{pH}$ dependent, with a plateau around $\mathrm{pH} 2$, which agrees with the site-dissociation theory [11] At $\mathrm{pH}>4$, however, the slope $\mathrm{d} V_{\mathrm{T}} / \mathrm{dpH}$ was $40 \mathrm{mV} / \mathrm{pH}$ for samples oxidized in dry oxygen, while oxides grown in steam at low temperatures had a $\mathrm{pH}$ sensitivity close to Nerstian However, after exposure to water for long periods, all oxides had a $\mathrm{pH}$ sensitivity in the range $30-40 \mathrm{mV} / \mathrm{pH}$ We have noted above that such exposure is expected to result in a high concentration of buried $\mathrm{OH}$ groups Thus, there is a correlation between a sub-Nernstian $\mathrm{pH}$ response and the number of buried $\mathrm{OH}$ sites We have found a similar correlation with surfaces of $E$-beam evaporated $\mathrm{Al}_{2} \mathrm{O}_{3}$, which combined low pH sensitivity and high hysteresis [67], a result we ascribed to porosity of the layer We conclude that bulk mechanisms tend to detract from the $\mathrm{pH}$ 
sensitivity of the surface This agrees with the fact that gel layer theories predict lower than Nernstian $\mathrm{pH}$ sensitivities [17]

Summarizing, the final picture emerging is that for ISFETs with gate materials which do not hydrate and are not porous, such as $\mathrm{S}_{3} \mathrm{~N}_{4}, \mathrm{Al}_{2} \mathrm{O}_{3}$ or $\mathrm{Ta}_{2} \mathrm{O}_{5}$ deposited by $\mathrm{CVD}$, surface effects dominate and these devices are accurately described by the site-dissociation theory The case of $\mathrm{SlO}_{2}$ is considerably more complex The site-dissociation theory only provides an accurate model for $\mathrm{SlO}_{2}$ near $\mathrm{pH} 2$, its point of zero charge Beyond $\mathrm{pH} 4$ or 5 , the slope is often lower than expected, and there is an additional slow response which results in hysteresis We propose that this is due to the presence of a large number of buried $\mathrm{OH}$ sites which are elther incorporated in the oxide during oxidation, or are subsequently formed by the exposure to water These sites have a slow $\mathrm{pH}$ response, which explains the hysteresis, and since it is a bulk response, its sensitivity tends to be lower, as mathematical treatments of such mechanisms have shown [18]

\section{Acknowledgements}

One of us ( $\mathrm{L} \mathrm{B}$ ) thanks the National Fonds voor Wetenschappelijk Onderzoek (of Belgium) for awarding him a fellowship

\section{References}

1 P Bergveld, IEEE Trans Blomed Eng, BME-17 (1970) 70

2 J Janata and $\mathrm{R} J \mathrm{~J}$ Huber, Ion-Select Electrode Rev, 1 (1979) 31

3 J Janata and R J Huber, in H Freser (ed), Ion Selective Electrodes in Analytical Chemistry Vol 2, Plenum, New York, 1980,p 107

4 R G Kelly, Electrochimica Acta, 22 (1977) 1

5 A G Revesz, Thin Solrd Fllms, 41 (1977) L43

6 P Bergveld, N F de Roolj and J N Zemel, Nature, 273 (1978) 438

$7 \mathrm{~N} F$ de Rooly and $\mathrm{P}$ Bergveld, in S T Pantelides (ed), The Physics of $\mathrm{SiO}_{2}$ and its Interfaces, Pergamon, New York, 1978, p 433

8 W M Siu and R S C Cobbold, IEEE Trans Electron Devices, ED 26 (1979) 1805

9 I R Lauks, IEEE Trans Electron Devices, ED 26 (1979) 1952

10 N F de Roojy and P Bergueld, Thin Soltd Films, 71 (1980) 327

$11 \mathrm{~L}$ Bousse, $\mathrm{N} F$ de Roolj and $\mathrm{P}$ Bergveld, IEEE Trans Electron Devices, ED-3O (1983) 1263

12 L Bousse, N F de Roolj and P Bergveld, Surface Science, 135 (1983) 479

$13 \mathrm{D} E$ Yates, $S$ Levine and $\mathrm{T} W$ Healy, J Chem Soc Faraday Trans I, 70 (1974) 1807

14 S D Moss, J Janata and C C Johnson, Analytical Chem, 47 (1975) 2238

$15 \mathrm{P}$ Bergveld, IEEE Trans Biomed Eng, BME 19 (1972) 342

$16 \mathrm{P} R$ Barabash and $\mathrm{R} \mathrm{S} \mathrm{C}$ Cobbold, IEEE Trans Electron Devices, ED 29 (1982) 102

$17 \mathrm{~J}$ Lyklema, $J$ Electroanal Chem, 18 (1968) 341

18 J W Perram, d Chem Soc Faraday Trans II, 69 (1973) 993

$19 \mathrm{D} E$ Yates and $\mathrm{T} W$ Healy, $J$ Collord Int Scr, 55 (1976) 9

20 W Smit, $C$ L $M$ Holten, $H$ N Stein, $J J M$ de Goely and $H M$ Theelen, $J$ Collold Interface Scl, 63 (1978) 120 
21 Y G Bérubé, G Y Onoda Jr and P L de Bruyn, Surface Sct, 7 (1967) 148

$22 \mathrm{~L}$ Bousse, $\mathrm{P}$ Bergveld and $\mathrm{W} \mathrm{E}$ van der Linden, in Electrochemical Detection in Flow analysis, Matrafured (Hungary) 1982, Akadémıa Kıadó, pp 257 - 265

23 B $H$ van der Schoul, $P$ Bergveld, $M$ Bos and L Bousse, Sensors and Actuators, 4 (1983) 267

$24 \mathrm{P}$ T McBride, J Janata, P A Comte, S D Moss and C C Johnson, Anal Chım Acta, 101 (1978) 239

25 S D Moss, J B Smith, P A Comte and C C Johnson, in P W Cheung et al (eds), Theory, Destgn, and Biomedical Applications of Solid-state Chemical Sensors, CRC Press, West Palm Beach, 1978, p 119

26 Pergveld, unpublished results

27 O Leistiko, Physica Scr, 18 (1978) 445

28 J F Schenck, in ref $[25]$ (p 165)

$29 \mathrm{H}$ Abe, M Esashı and T Matsuo, IEEE Trans Electron Devices, ED.26 (1979) 1939

30 J Crank, The Mathematics of Diffusion, Oxford University Press, London, 1956, p 121

31 M R Boudry and J P Stagg, J Appl Phys, 50 (1979) 942

32 D J DiMarıa, J Appl Phys, 48 (1977) 5149

33 E H Snow, A S Grove, B E Deal and C T Sah, J Appl Phys, 36 (1965) 1664

34 S R Hofstein, IEEE Trans Electron Dev, E,D-19 (1967) 749

35 A G Tangena, N F de Roolj and J Middelhoek, $J$ Appl Phys, 49 (1978) 5576

36 M Németh-Sallay, R Szabó, I C Szép and P Tutto, Thin Soltd Fulms 70 (1980) 37

37 S I Raider and R Flitsch, $J$ Electrochem Soc, 118 (1971) 1011

38 M W Hullen, Thesis, Rijksunversitedt Gronmgen, The Netherlands, 1981

39 B Yurash and B E Deal, $J$ Electrochem Soc, 115 (1968) 1191

$40 \mathrm{R}$ H Doremus, Phys Chem Glasses, 10 (1969) 28

41 R H Doremus, Glass Science, Wiley, New York, 1973, p 172

$42 \mathrm{P} J$ J Jorgensen and F J Norton, Phys Chem Glasses, 10 (1969) 23

43 G Hetherington, K H Jack and M W Ramsay, Phys Chem Glasses, 6 (1965) 6

44 F G K Baucke, J Non-Cryst Sol, 40 (1980) 159

45 J B $\phi$ ttuger, J $R$ Leslie and N Rud, J Appl Phys , 47 (1976) 1672

46 A Wlkby, Electrochimica Acta, 19 (1974) 329

47 R H Doremus, $J$ Non-crystal Sol, 19 (1975) 137

48 I A van Lier, $P$ L de Bruyn and $J$ Th $G$ Overbeek, $J$ Phys Chem, 64 (1960) 1675

$49 \mathrm{R}$ K Iler, The Chemistry of Silica, Wiley, New York, 1979

$50 \mathrm{H} N$ Steun, Advan Collozd Interface Sci, 11 (1979) 67

$51 \mathrm{R} M$ Cohen, $\mathrm{R}$ J Huber, J Janata, $\mathrm{R} W$ Ure Jr and S D Moss, Thin Solid Films, $53(1978) 169$

52 L Bousse and $P$ Bergveld, $J$ Electroanal Chem, 152 (1983) 25

53 G L Holmberg, A B Kuper and F D Mrrald1, J Electrochem Soc, 117 (1970) 677

54 A Hartstein and D R Young, Appl Phys Lett, 38 (1981) 631

55 R Pfeffer, $R$ Lux, H Berkowitz, W A Lanford and C Burman, $J$ Appl Phys, 53 (1982) 4226

56 S Krongelb, J Electrochem Soc, 116 (1969) 1583

57 D M Gruen, B Siskind and R B Wright, J Chem Phys, 65 (1976) 363

58 F G K Baucke, J Non-Cryst Sol, 19 (1975) 75

$59 \mathrm{D} N$ Furlong, $\mathrm{D}$ E Yates and $\mathrm{T}$ W Healy, in $\mathrm{S}$ Trassattı (ed ), Electrodes of Conductuve Metalluc Oxudes, Part B, Elsevier, Amsterdam, 1981, p 367

60 Yu G Vlasov, Yu A Turantuv, A P Baraban and V P Letavm, Zh Prikl Khım, 53 (1980) 1980 Translated as J Appl Chem USSR, 1449 (1980)

61 Luc Bousse, Thesss, Twente University of Technology, The Netherlands, 1982

$62 \mathrm{E} \mathrm{H}$ Nicollian, $\mathrm{C} \mathrm{N}$ Berglund, P F Schmidt and J M Andrews, $J$ Appl Phys, 42 (1971) 5654 
63 C D Fung, $\mathrm{P}$ W Cheung and $\mathrm{W} \mathrm{H}$ Ko, Int Electron Devees Meeting, Washington, $D C, 1980, p 689$

$64 \mathrm{~J}$ F Schenck, $J$ Collozd Interface Scı, 61 (1967) 569

65 F W Cheung, W II Ko, D J Fung and S II Wong, in ref [25] (p 91)

$66 \mathrm{Yu} G$ Vlasov, Yu A Tarantov, V P Letavin and A P Baraban, Zh Prtkl Khtm, 55 (1982) 459 Translated as $J$ Appl Chem USSR, 420 (1982)

67 Unpublished results

68 J P Stagg, Appl Phys Lett, 31 (1977) 532

$69 \mathrm{R} J$ Kriegler and T F Devenyı, Thin Soltd Fllms, 36 (1976) 435

70 S R Hofstein, Appl Phys Lett, 10 (1967) 291

$71 \mathrm{G} H$ Frischat, Ionic Diffusion in Oxide Glasses, Trans Tech, Aedermannsdorf, 1975

72 F G K Baucke, $Z$ Naturforschung 26a (1971) 1778

\section{Biographies}

Plet Bergueld was born in Oosterwolde, the Netherlands, on January 26, 1940 He recelved the M S degree in electrical engineernng (electronics) from Eindhoven University of Technology, Eindhoven, the Netherlands, in 1965, and the $\mathrm{Ph} \mathrm{D}$ degree from Twente University of Technology, Enschede, the Netherlands, in 1973

Since 1965 he has been a member of the Bio-information Group, Department of Electrical Engineering, Twente University of Technology $\mathrm{He}$ is also a member of the Coordination Centre for Biomedical Engineering and a member of the Research Unit Sensors and Actuators of this University In 1981 he became a member of the Semiconductor Group of the Foundation for Fundamental Research on Matter in the Netherlands

The subject of his dissertation was the ion-sensitive field-effect transistor (ISFET) and the OSFET $\mathrm{He}$ is involved in research on electronic measuring and stimulating methods in physiological systems, with special attention for in vivo biosensors He lectures on biomedical instrumentation for graduate students of Twente University of Technology and medical personnel of affiliated hospitals

In 1984 he was appointed as full professor in biosensor technology at the Twente University of Technology

Luc Bousse was born in Brussels, Belglum in 1955 In 1977 he recelved the electrical engineer's degree from the Vrije Unıversiteit Brussel He stayed on as a research fellow at the Brussels University until 1979 Since 1980 he has been with the Biosensors group of the Twente University of Technology, the Netherlands, where he recelved the Ph D degree in 1982

He is currently working on the physical mechanisms of chemically sensitive electronic devices, and their applications at Stanford University 